\title{
Cooperation and the In-Group-Out-Group Bias: A Field Test on Israeli Kibbutz Members and City Residents
}

\author{
Bradley J. Ruffle* \\ Department of Economics \\ Ben-Gurion University \\ Beer Sheva, Israel \\ 84105 \\ bradley@bgumail.bgu.ac.il
}

\author{
Richard Sosis ${ }^{*}$ \\ Department of Anthropology \\ $\mathrm{U}-2176$ \\ University of Connecticut \\ Storrs, CT 06269-2176 \\ richard.sosis@uconn.edu
}

July 2004

\begin{abstract}
The in-group-out-group bias is among the most well documented and widely observed phenomenon in the social sciences. Despite its role in hiring decisions and job discrimination, negotiations, and conflict and competition between groups, economists have paid little attention to the in-group-out-group bias. We question the universality of the bias by conducting field experiments to test whether it extends to the cooperative behavior of one of the most successful and best-known modern collective societies, the Israeli kibbutz. The facts that kibbutz members have voluntarily chosen their lifestyle of cooperation and egalitarianism, the ease with which they could join the surrounding capitalist society and their disproportionate involvement in social and national causes suggest that if ever there was a society of individuals whose cooperativeness extends equally to members and non-members, the kibbutz is it. Nonetheless, our results indicate that kibbutz members display higher levels of cooperation when paired with anonymous kibbutz members than when paired with city residents. In fact, when paired with city residents, kibbutz members' observed levels of cooperation are identical to those of the city residents. Moreover, we show that self-selection rather than kibbutz socialization largely accounts for the extent to which kibbutz members are cooperative.
\end{abstract}

keywords: cooperation, in-group-out-group bias, field experiment, self-selection, socialization, kibbutz.

JEL classification codes: C72, C93, P32.

\footnotetext{
${ }^{*}$ Correspondence to: Bradley Ruffle, fax: 972-8-6472941, phone: 972-8-6472308.

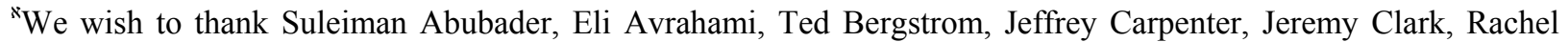
Croson, Guillaume Frechette, Yaakov Gilboa, Todd Kaplan, David Reiley, Moshe Schwartz, Robert Slonim, Orit Tykocinski, an anonymous referee of this journal and seminar participants in the Behavioral Decision-Making Forum at Ben-Gurion University and the 2002 AEA meetings in Atlanta for valuable comments. Our team of experimenters deserves special thanks: David Amar, Yifat Arbeli, Guy Attias, Inbar Avraham, Revital Chapani, Moti Dahan, Gil Eichholz, Sarit Fhima, Hagit Gilad, Tsahi Hasday, Avi Levy, Ronen Matmon, Hila Moshkovits, Limor Polak, Tata Pyatigorsky-Ruffle, Ze'ev Shtudiner, Amihai Toledano and Limor Zahavi. We also thank the kibbutz movements for their cooperation and Yad Tabenkin for agreeing to provide economic data. This version of the paper was completed during Ruffle's sabbatical at the Harvard Business School. He thanks them and Alvin Roth in particular for their hospitality and support. Funding for this project has been provided by grants from the Binational Science Foundation, the Pinhas Sapir Center for Development, the Ushi Friedman Foundation and the University of Connecticut Large Faculty Grants.
} 


\section{Introduction}

The in-group-out-group bias is among the most well documented and widely observed phenomenon in the social sciences. Alternatively known as the intergroup bias, in-group favoritism and the minimal groups paradigm, the in-group-out-group bias refers to the tendency to evaluate one's own group or its members (the in-group) more favorably than groups to which one does not belong and its members (the out-group). Literally hundreds of in-group-out-group bias studies fill psychology and sociology journals (see Hewstone et al., 2002, for a recent survey and Rabbie and Horowitz, 1969, Tajfel et al., 1971, and Brewer and Campbell, 1976, for a few of the classic references). This vast literature has demonstrated, among other findings, the ease with which group identity may be called upon or created, the robustness of the bias to different cultures and societies, motivational and cognitive explanations for its existence, and methods to moderate the bias. By contrast, economists have paid little attention to the bias, ${ }^{1}$ despite its obvious economic implications for negotiations, conflict resolution, competition between groups, international trade agreements, hiring decisions and job discrimination, and a spate of issues related to fairness, cooperation and trust.

In this paper, we question the universality of the intergroup bias. We design controlled field experiments to test whether the bias extends to the cooperative behavior of members of one of the most successful communal movements in history, the Israeli kibbutz. Kibbutz members live together, typically work and socialize together, and share equally all earned income, independent of an individual member's occupation, skills or work effort. What is so striking about the egalitarian and cooperative practices of the kibbutz are their voluntary nature.

\footnotetext{
${ }^{1}$ Exceptions include Buchan et al. (forthcoming) who study trust and trustworthiness in the investment game with American students who display an ingroup bias, Japanese and Korean students don't, and Chinese students who actually trust and reciprocate more with outgroup members. Carpenter and Cardenas (2004) examine extraction rates of Colombian students, American students and mixed groups of Columbian and American students in a commonpool-resource experiment and find Colombians increase their extraction in the mixed groups, Americans reduce theirs, leaving the overall rate of extraction unaffected.
} 
Members of the kibbutz have freely chosen their lifestyle. They have intentionally removed themselves from mainstream capitalist society to pursue an ideology of socialism and cooperation. If they so desire, kibbutz members may freely abandon the way of life on the kibbutz to (re)join Israeli capitalist society. The fact that kibbutz members are ethnically, culturally, linguistically and visibly indistinguishable from other Israelis testifies to their very low barriers and costs to exiting the kibbutz and the ease with which they may (re)enter the surrounding capitalist culture. It follows that those who choose to join the kibbutz most likely do so out of a desire to live by its egalitarian and cooperative precepts.

Moreover, the raison d'etre and lifestyle of the kibbutz socialize individuals to cooperate not only with one another, but also with Israelis more generally. Ben-Rafael (1997) summarizes the three central components of kibbutz identity as a sense of community grounded in cooperation and egalitarianism, entrepreneurship, and social elitism. By social elitism BenRafael means that kibbutz members perceive their involvement and leadership in social and national causes as their duty. Indeed, a recently formed organization of traditional kibbutzim known as "HaZerem HaShitufi" (The Cooperative Trend) publicizes as part of its stated goal that, "we have to dedicate ourselves to the building of a better society. The kibbutz must respond to the challenge and ... be the pioneer leading the crowd" (Ben-Rafael, 1997, p. 20; Frank et al., 1988, p. 53). Kibbutz members have always perceived themselves and portrayed themselves to outsiders as willing to sacrifice their own material well-being for the benefit of Israeli society. Putting their lives at risk, early kibbutz members played a central role in the establishment and defense of modern Israel and in the determination of its borders. Although somewhat less dramatic, kibbutz members' continued sacrifice today can be seen in their keen involvement in various forms of voluntary social, national and military service. Kibbutz members are disproportionately represented in the Israeli army's combat units, volunteer youth groups, 
community service projects such as the absorption of new immigrants, and in public service positions (see e.g., Kahane, 1983).

In short, kibbutz members' freely chosen lifestyle of egalitarianism and cooperation despite possibly more lucrative outside opportunities indicates a commitment to these ideals. Furthermore, the historical role of the kibbutz in founding the modern State of Israel and the continued service of kibbutz members to Israeli society constitute evidence that kibbutz members' cooperative philosophy extends to Israeli society at large. Together these observations suggest that if ever there was a society of individuals whose cooperativeness extends equally to members and non-members, the kibbutz is it. Such a finding would constitute a counterexample to the universality of the in-group-out-group bias.

To evaluate whether kibbutz members cooperate to the same degree with fellow kibbutz members and non-members, we design a common-pool resource dilemma game conceptually similar to the sorts of day-to-day consumption problems confronted by kibbutz members. The game is conducted in pairs. In one treatment, kibbutz members from the same kibbutz are anonymously paired with one another. In the other treatment, kibbutz members are paired with Israeli city residents. By comparing kibbutz members' cooperative behavior in these two treatments we are able to determine if kibbutz members are indeed equally cooperative toward members and non-members, or if they behave less cooperatively toward non-members. Moreover, our second treatment allows us to determine whether kibbutz members are more cooperative individuals than city residents. In addition, data collected during post-experiment interviews allows us to assess to what extent kibbutz socialization versus self-selection contribute to the cooperativeness of kibbutz members.

In the next section, we provide some background on the Israeli kibbutz. Section 3 discusses the samples of kibbutzim (the plural of kibbutz) and cities selected for our research. 
Section 4 details the experimental game, procedures and hypotheses. The results are presented in section 5 and interpreted in section 6 . Section 7 concludes.

\section{The Israeli Kibbutz}

The kibbutz was originally conceived as a small collective farming settlement in which members based their social and cultural lives on the collective ownership of property and wealth. The first kibbutz, Degania, was established in the Galilee in 1909. Today, the more than 270 kibbutzim are modern cooperative communities engaged in the production of the entire gamut of goods and services in high technology, manufacturing, tourist and agricultural industries using the most modern production techniques. The approximately 124,000 individuals currently living on kibbutzim comprise around $2 \%$ of the Israeli population.

The kibbutz developed out of a socialist egalitarian ideology as well as the pragmatism of group living by Eastern European Jews during the years leading up to the establishment of the modern State of Israel. Guided by the dictum "from each according to his abilities, to each according to his needs," the traditional model of the kibbutz prescribes that each member receives food, shelter, clothing, education, health care, and an equal share of the income generated by the kibbutz. That all kibbutz members earn an equal income holds whether one is the dishwasher in the communal dining hall, the CEO of the computer chip plant, the kibbutz gardener or retired. Income on the kibbutz is thus divided equally regardless of profession, skill or effort level. In this sense, the generation of income or production is a public-good problem. Consumption on the kibbutz, by comparison, represents a classic tragedy of the commons problem: kibbutz members enjoy equal and unrestricted access to non-renewable consumption goods. For example, the costs associated with a member's consumption of food, water,

electricity and the use of communal cars are borne by the kibbutz, not the individual. 
Cooperation and self-restraint are thus necessary to prevent the depletion of these common-pool resources and to ensure the continuity of the kibbutz. ${ }^{2}$

The continuation of the kibbutz should not be regarded as self-evident in view of the decline of many kibbutzim that began in the mid-1980s. Concern for economic viability on these faltering kibbutzim set in motion numerous structural changes that transfer the control of certain resources and the costs of consumption from the collective to the individual household. The most radical change in this process referred to as "privatization" permits differential salaries between kibbutz members. ${ }^{3}$

\section{Sample}

For the purposes of this paper, we chose four highly collectivized (non-privatized) kibbutzim. ${ }^{4}$ The four participating kibbutzim were established between 1943 and 1949, are located in central and southern Israel, each with between 500 and 700 members, and all moderately to very economically successful. We also selected neighborhoods in seven towns and cities in central and southern Israel to match the different standards of living among our four sample kibbutzim. These cities are Beer Sheva, Hadera, Maitar, Omer, Or Yehuda, Rehovot and Rishon Lezion.

\section{Experimental Hypotheses, Design and Procedures}

\subsection{Experimental Design}

The logistics of our field experiments and the nature of our subject pool raise several essential considerations in the choice of an experimental game. ${ }^{5}$ First, kibbutz members live together, and

\footnotetext{
${ }^{2}$ See Ostrom, Gardner and Walker (1994) for a thorough theoretical, experimental and empirical treatment of common-pool resources.

${ }^{3}$ Ben-Rafael (1997) provides an excellent treatment of the economic and social changes on the kibbutz that accompanied privatization.

${ }^{4}$ Using data collected by Shlomo Getz on the number of privatization changes adopted by each kibbutz, the four kibbutzim in our sample made between one and four changes (out of a possible 23).

${ }^{5}$ Our use of a laboratory experiment on kibbutz members makes these "synthetic field experiments" in Harrison and List's (forthcoming) taxonomy of field experiments.
} 
work and socialize with one another on a daily basis. Assuring subject anonymity is therefore of prime importance. For this reason, we chose to conduct these experiments in the privacy of the individual members' homes rather than in a communal space. Second, to allow for the comparison of kibbutz members' choices with those of city residents when the two groups are matched with one another, we require a symmetric game.

We selected a one-shot game for two reasons. First, we wanted to capture participants' initial willingness to cooperate. Our question of interest is not whether kibbutz members are able to learn to cooperate with city residents to the same degree that they cooperate with members of their own kibbutz. A more obvious reason for the choice of a one-shot game is that a repeated game complicates considerably subjects' decision task by introducing additional strategic considerations. Given the diversity of the subject pool in terms of education, age and occupation, we sought a conceptually simple game.

As for the particular nature of the experimental game, issues of cooperation and selfrestraint confront kibbutz members on a daily basis. As discussed in section 2, almost all consumption goods on a kibbutz are common-pool resources in the sense that they are exhaustible and equally accessible to all kibbutz members. We therefore wanted a game that captures an element of the common-pool resource dilemmas familiar to kibbutz members.

The experimental game we use is conducted in pairs. There are 100 shekels available in a joint envelope to which each pair member has access. ${ }^{6}$ Each pair member independently decides how much of the available 100 shekels to remove from the envelope to keep for himself. A kibbutz member may remove any amount between 0 and 100 inclusive. If the sum of the amounts of money removed exceeds 100 shekels, then both players receive zero and the game is over. If the sum of the amounts removed is less than or equal to 100 , then each player keeps the 
respective amount that he removed. In addition, whatever money is leftover is multiplied by 1.5 and divided equally between the two players. ${ }^{7}$

We conducted two versions of this game. In one version, two kibbutz members from the same kibbutz were anonymously paired with one another (to be referred to as the kibbutz-kibbutz or in-group treatment). In the other version, a kibbutz member was paired with a city resident (to be referred to as the kibbutz-city or out-group treatment). The kibbutz member and the city resident in the kibbutz-city treatment were given precisely the same information, namely, that the person with whom they were paired was from another place. ${ }^{8}$ It was important for us not to specify more precisely the location of the paired partners to control for possible stereotypes about kibbutz members or residents of certain cities. ${ }^{9}$ Given the demographics of Israel (kibbutz members constitute only $2 \%$ of the population), it is most probable that kibbutz members (correctly) believed they were paired with city residents and that city residents believed they were paired with residents from different cities. Appendix B contains the instruction sheet as well as an introductory statement read aloud to each subject at the beginning of the experiment. ${ }^{10}$

Note that any pair of amounts that sum to 100 is a Nash equilibrium of this game. For any amount, $x_{j}$, that player $j$ removes from the envelope, player $i$ 's best response is to remove 100 minus $x_{j}$. However, the Nash equilibria of this game are socially inefficient: the sum of the pair's

\footnotetext{
${ }^{6}$ At the time these experiments were conducted, 4 Israeli shekels equaled approximately $\$ 1$ US. The average monthly salary of a kibbutz member in this four-kibbutz sample is approximately 700 shekels, a sizable amount given that the kibbutz covers most of its members' basic expenses (e.g., housing, food, utilities).

${ }_{7}^{7}$ We considered an alternative design in which each pair member is restricted to claim an amount between 0 and 50 shekels of the total 100 shekels. The amounts that each player leaves in the envelope are summed together, multiplied by 1.5 and divided equally between the two players. Feedback from student subjects from pilot experiments indicated that they found this design considerably more difficult to understand than the one presented above. For this reason, we settled on our particular design.

${ }^{8}$ In the original Hebrew, the word "yishuv" was used, which can be translated as city, town or populated area.

${ }^{9}$ To see this, suppose we had told the city resident that he was paired with a kibbutz member. This knowledge may have led the city resident to remove less money because, for instance, he believes that kibbutz members are generally cooperative. Similarly, indicating to the kibbutz member that he is paired with a resident of Beer Sheva, for instance, would have allowed existing stereotypes (about residents of Beer Sheva, a predominantly Sephardic, working class city) to influence the decision of the kibbutz member.

${ }^{10}$ Both forms as well as the post-experiment questionnaire are translations from the original Hebrew versions and are available from the authors upon request.
} 
payoffs is higher if together they remove less than 100 . The socially optimal outcome is achieved when both players remove $0 .{ }^{11}$

The amount a player removes therefore provides a measure of his cooperativeness. For every shekel a player leaves in the envelope, he adds three-quarters of a shekel to his opponent's payoff and three-quarters of a shekel to his own payoff, provided their claims sum to less than 100. That the subject fears his partner will claim a large amount (i.e., that the sum of the amounts will exceed 100) is an alternative explanation for a small amount removed from the envelope. To help identify the motivation behind a subject's claim, we asked each participant to indicate the amount he believed his partner would remove ${ }^{12}$ and the reason why the participant chose to claim the amount that he did.

\subsection{Experimental Procedures}

To the extent possible, subjects from the kibbutzim and from the cities were recruited using the same methods. A letter of introduction describing the nature of the research, the sources of funding and a request to participate was sent to every household on the four kibbutzim as well as to every household in the target areas within each of our seven cities. These letters were mailed out to all households on the kibbutz about a week before our planned visit to the kibbutz. In the case of the city residents, because city telephone books are not organized by address, we distributed the letters by hand to households in the neighborhoods of the cities we intended to visit. One or two days before our visit, we telephoned kibbutz members inviting them to participate in the research and, for those who agreed, slotted them for a specific time. Omer, a

\footnotetext{
${ }^{11}$ Our game resembles the Nash demand game (Nash, 1953). The difference is that whatever money is leftover in our game is multiplied by 1.5 (rather than disappears) and divided equally between the two players. This distinction encourages players to remove less money so that more is available for the pair. In the Nash demand game, the Nash equilibria and socially optimal outcomes coincide.

${ }^{12}$ We elicited subjects' first-order beliefs with a simple hypothetical question. Since our focus is on the amounts subjects remove from the envelope, we preferred not to complicate their decision task with an incentive compatible mechanism for beliefs.
} 
suburb of Beer Sheva, was the one location in our sample with its own telephone book small enough to be able to follow up the letter drop-offs by searching through the telephone book for the addresses that received the letter of invitation. These residents were telephoned and invited to participate in the research. For the remaining six cities, the letters of introduction were made more specific to indicate that we would be visiting their homes on a given day within an indicated two to three-hour window.

To facilitate data collection and to minimize the chances that kibbutz members who completed the experiment could contact others who may be scheduled to participate, 20 BenGurion University graduate and undergraduate economics students (who had completed a class in experimental economics) were trained and employed. Between 8 and 14 subjects (i.e., between 4 and 7 pairs) participated simultaneously at any given time.

Upon arrival at the kibbutz, each experimenter searched for the home of his first subject. Once an experimenter arrived at a subject's home (kibbutz member or city resident), he called the other experimenter by cellular phone to let him know that he had arrived. He then awaited the phone call of the other experimenter so that both experimenters could enter their respective subjects' homes simultaneously. This ensured that the paired subjects began the experiment at the same time.

Upon entering the subject's home, the experimenter introduced himself and requested a quiet place where they could sit undisturbed for the next 30 minutes. Once seated, the experimenter conveyed some preliminary details concerning the experiment (e.g., decisions will be used for research purposes only, participants will remain anonymous, and other details contained in Appendix B). The subject was then given the instruction sheet and told to take his time and read the instructions carefully. Once finished, the experimenter read the instructions aloud. To ensure full comprehension of the game, two numerical examples were performed. In each example, a pair of numbers was randomly drawn from a bag containing numerical values 
between 0 and 100. The numbers were meant to be the amounts chosen by two hypothetical participants in the experimental game.

After any clarifying questions were answered, a decision was elicited regarding the amount the subject wished to remove from the envelope, immediately followed by the amount the subject believed the other person would remove from the envelope. The experimenter of the subject who decided first telephoned the other experimenter by cellular phone and informed him that a decision had been reached. ${ }^{13}$ The experimenter did not convey the amount of the decision in this conversation in order to avoid any reaction or facial expression on the part of the second experimenter, which could influence the second participant's decision. After the second subject decided upon an amount to remove from the envelope and the amount he believed his opponent would remove, that subject's experimenter telephoned the first experimenter, and the decisions were exchanged and conveyed to the subjects along with their resultant earnings.

\subsection{Experimental Hypotheses}

Our two experimental treatments allow us to test two main hypotheses. First, kibbutz members are expected to cooperate equally with members and non-members. Kibbutz members have traditionally displayed a strong willingness to sacrifice for the benefit of Israeli society at large. Moreover, their choice to join or remain on the kibbutz suggests they are motivated by cooperative ideals. Research by Mann, Radford and Kanagawa (1985) indicates that the distinction between in-group and out-group is markedly less pronounced in collectivist societies than in individualist ones. The kibbutz is the definitive collectivist society.

${ }^{13}$ Cellular phones were used instead of the kibbutz member's home phone to prevent the subject from discovering the identity of his paired partner from his phone bill, from the call display or call return features, or by dialing the operator and asking. 
If kibbutz members do not cooperate equally with out-group and in-group members, their values and the lifestyle promoted by the kibbutz suggest that they can at least be expected to cooperate more with outsiders than outsiders cooperate with others.

Finally, the amount a subject removes from the envelope may be motivated by a fear of exceeding the available 100 shekels, a pure preference for cooperation or an anticipated reciprocation of cooperative behavior. Subjects' estimates of their opponents' claims will help us to distinguish between these competing motives.

\section{Results}

A total of 110 kibbutz members participated in the kibbutz-kibbutz treatment. An additional 61 kibbutz members participated in the kibbutz-city treatment against 61 city residents. The proportions of kibbutz members from each of the four kibbutzim were held constant across the two treatments. As a result, any possible kibbutz-specific effects are irrelevant for testing our hypotheses. Table 1 presents summary statistics for the amounts claimed and the amounts predicted the opponent would claim, as well as a number of demographic variables for each of the sample populations. Like the larger Israeli population, the subjects are on the whole well educated, namely, high school educated plus approximately two years of post-secondary education on average. The facts that compared to kibbutz members, city residents are on average ten years younger and more likely to be native Israelis reflects the aging kibbutz population, its eldest generation consisting primarily of European immigrants.

[insert Table 1 here]

One cursory measure of the degree of cooperation exhibited in this game is the observation that there were no pairs in either treatment whose claims exceeded the Nash equilibrium outcome of 100 . Furthermore, in the kibbutz-kibbutz treatment, all 55 pairs chose amounts that sum to strictly less than 100. By contrast, five pairs of subjects in the kibbutz-city 
treatment played the Nash equilibrium; in all five cases, both pair members claimed 50 shekels. These observations along with the histograms in Figure 1 point to our first main result.

\section{Result 1: Kibbutz members take out less when paired with other kibbutz members than when paired with city residents.}

[insert Figure 1 here]

As indicated in the first column of Table 1, kibbutz members take out on average 29.6 shekels $($ median $=35)$ when paired against other kibbutz members compared to 35.2 shekels (median $=40)$ when paired against city residents (t-test of means $=2.31, p=.02, \mathrm{df}=147$, equal variances not assumed here and hereafter). ${ }^{14}$ Regression equations (1) and (2) in Table 2 provide further support for the relative cooperativeness of kibbutz members in the in-group treatment. Our model of a subject's decision to remove a specified amount from the envelope includes the amount he believes his opponent will remove ("predict"), as well as dummy variables for kibbutz members in the in-group treatment and city residents (kibbutz members in the out-group treatment serve as the baseline category). ${ }^{15}$ The highly significant coefficients of -5.63 and -5.01 on the "kibbutz ingroup" variable indicate that, controlling for other explanatory variables, kibbutz members in the in-group treatment claim five shekels less than their cohorts in the outgroup treatment. $^{16}$

[insert Table 2 here]

\footnotetext{
${ }^{14}$ Alternatively, the nonparametric Wilcoxon-Mann-Whitney rank-order test rejects the null hypothesis that the two distributions of amounts removed from the envelope come from the same underlying population distribution at the $5 \%$ level ( $p$-value=.049). More generally, the Wilcoxon-Mann-Whitney test yields results qualitatively identical to all of the $\mathrm{t}$-tests of means reported in this paper.

${ }^{15}$ Variables for years of education, sex and other demographic variables are not significant and have therefore been omitted from the table.

${ }^{16}$ For each of our specifications, we also estimated left-censored Tobit regressions to account for the censored observations at 0: perhaps these subjects would have claimed negative amounts (i.e. to contribute money from their pockets to the envelope) had the option been available. In actual fact, with only 19/231 (8.2\%) censored observations, all of the Tobit estimates and their marginal effects are very similar to the corresponding OLS coefficients.
} 
One may argue that kibbutz members claim smaller amounts when paired with other kibbutz members due to increased ambiguity aversion in this treatment, and not because they choose to behave more cooperatively. Stated explicitly, not knowing the amount one's opponent will claim or even the probabilities associated with different amounts, kibbutz members in the kibbutz-kibbutz treatment place a higher subjective probability that the sum of the requests will exceed 100 than those in the kibbutz-city treatment and therefore they choose to remove smaller amounts. In order to assess this alternative explanation for our finding, we asked participants, after they made their decision and before they were informed of their partner's decision, the amount they believed their partner would request from the envelope. The predict variable in Table 1 allows us to reject this alternative hypothesis: kibbutz members actually predict that other kibbutz members will remove slightly less (mean=40.4, median=46.5) than kibbutz members paired with city residents (mean $=41.3$, median $=50)$, $\mathrm{t}$-stat $=0.41, \mathrm{p}=.68, \mathrm{df}=140$. What is more, the positive and highly significant coefficient on the predict variable in regression (2) of Table 2 indicates that for every shekel a kibbutz member believes his partner will claim, he claims an additional 0.6 shekels. Without concluding causality, these observations together with Result 1 suggest that kibbutz members' higher levels of cooperation toward one another than toward city residents may follow in part from an expectation of reciprocal cooperation. The less a kibbutz member believes his opponent will claim, the more he is willing to cooperate by claiming less. That individuals determine their willingness to cooperate as a function of their beliefs about others' likelihood of cooperation is among one of the most robust and central findings in other social dilemma games (Ostrom, 2000, p. 140) and motivates Rabin's (1993) model of reciprocal fairness.

In summary, kibbutz members behave less cooperatively toward city residents than toward members of their own kibbutz. Still, how does their level of cooperative behavior compare with that of the city residents? 


\section{Result 2: When kibbutz members are paired with city residents they exhibit levels of cooperation indistinguishable from city residents.}

The histograms in Figure 2 reveal that the distributions of the amounts claimed for kibbutz members and city residents in the kibbutz-city treatment are strikingly similar.

[insert Figure 2 here]

Forty shekels is the modal claim in both population groups. City residents claimed an average of 35.6 shekels (median $=40$ ) compared to an average of 35.2 shekels by kibbutz members $($ median $=40)$. A t-test of means confirms that this difference is not significant ( $\mathrm{t}$ stat $=0.16, \mathrm{p}=.87, \mathrm{df}=118$ ). Furthermore, the OLS regressions reported in (1) and (2) of Table 2 indicate no difference in the decisions of kibbutz members and city residents: the dummy variable "city resident" is not statistically different from zero. The interpretation of this result is that outside of their communities, kibbutz members are no more cooperative than members of the surrounding capitalist economy.

Taken together, Results 1 and 2 suggest that kibbutz members are not equally cooperative toward members and non-members alike, but rather they are conditional cooperators. ${ }^{17}$ One interpretation of this conclusion is that the kibbutz has not succeeded in creating universally cooperative individuals. Such an interpretation may be premature since the majority of kibbutz members (131/171 in our sample) were born off the kibbutz. Result 3 addresses the role kibbutz socialization plays in the cooperative behavior of kibbutz members.

\footnotetext{
17 Ostrom (2000) and Schram (2000), among others, use the term "conditional cooperation" to refer to a motivational state defined by the willingness to cooperate if and only if one perceives gains from cooperation. In our context, one's willingness to cooperate varies in accordance with whom one is matched. This variation, particularly in one-shot games (such as the one used in this paper), may stem from a pure preference rather than from any perceived benefits from cooperation. This distinction may be likened to that between a "taste for discrimination" (a preference) and "statistical discrimination" (based on expected gains) (Becker, 1957).
} 


\section{Result 3: The larger the fraction of one's life spent on the kibbutz, the less cooperatively one behaves toward fellow kibbutz members.}

According to Result 3, the more time a kibbutz member has lived on the kibbutz (controlling for age), the less he can be expected to cooperate with his fellow kibbutz members. To demonstrate this result, we constructed a variable that measures the fraction of the kibbutz member's life spent on the kibbutz. This variable, "frackib", is calculated as the year the experiments were conducted (2000) minus the year the member arrived on the kibbutz, divided by the member's age. In regression (3) of Table 2 we interacted frackib with the treatment in which the kibbutz member participated ("kibbutz ingroup" or "kibbutz outgroup"). The interaction term "frackib*kibbutz outgroup" is not different from zero, suggesting that the cooperativeness of kibbutz members toward city residents does not depend on how long the member has lived on the kibbutz. By contrast, the highly significant coefficient of 10.21 on "frackib*kibbutz ingroup" means that in the kibbutz-kibbutz treatment someone born on the kibbutz can be expected to remove about ten shekels more than a new arrival. The results from these interaction terms along with the significant coefficient of -9.03 on the kibbutz ingroup dummy variable imply that kibbutz members in the kibbutz-city treatment and those born on the kibbutz in the kibbutz-kibbutz treatment claim similar amounts; it is new kibbutz members who are distinctly cooperative in their play against fellow kibbutz members.

More direct evidence that those born on the kibbutz are less cooperative toward fellow kibbutz members than members who arrived from the outside comes from regression (4). We interacted the dummy variables "born on kibbutz" (equal to one if the kibbutz member was born on the kibbutz and zero otherwise) and "1 - born on kibbutz" (i.e. not born on the kibbutz) with each of the treatments (kibbutz ingroup and kibbutz outgroup), with kibbutz members born off the kibbutz who played in the kibbutz-kibbutz treatment ("1 - born on kibbutz* kibbutz ingroup") 
as the omitted category. None of the coefficients of the three included groups is significantly different from any other; however, all three are positive and significant, again pointing to the uniquely cooperative behavior of kibbutz members not born on the kibbutz toward fellow members. For example, the coefficient of $6.05(\mathrm{p}=.057)$ on "born on kibbutz*kibbutz ingroup" indicates that members born on the kibbutz in the kibbutz-kibbutz treatment remove six shekels more than their cohorts who joined the kibbutz from the outside. Similarly, in the kibbutz-city treatment, kibbutz members born on the kibbutz and those born off the kibbutz claim, respectively, 8.37 and 5.86 shekels more than members born off the kibbutz in the kibbutzkibbutz treatment. These results control for the number of years the member has lived on the kibbutz ("years on kibbutz"). The positive and significant coefficient on this variable also attests to declining cooperation as a function of years lived on the kibbutz. ${ }^{18}$

The interpretation of Result 3 is that self-selection accounts significantly for the extent to which kibbutz members cooperate with one another. Those who have chosen or been recruited to join the kibbutz are more cooperative than those raised on the kibbutz. This finding does not bode well for the future of cooperation on kibbutzim that have found it increasingly difficult to attract new members from the outside in recent years.

The most plausible explanation for this provocative finding is that the conscious choice to leave capitalist society and join the kibbutz at a later age in life reflects a commitment and loyalty to the cooperative ideology of the kibbutz. These kibbutz members have self-selected cooperation as a way of life as revealed by their decision to join the kibbutz. By comparison, kibbutz members born and raised on the kibbutz likely have other, less ideological and more practical reasons for remaining on the kibbutz, such as familiarity with the environment, lower

\footnotetext{
18 For this specification, we use the number of years the member has lived on the kibbutz, rather than age, as a control. Because all four kibbutzim in our sample were founded no earlier than 1943, all of our subjects over the age of 57 (at the time this research was conducted) were necessarily born off the kibbutz. Thus, "born off the kibbutz" and age are collinear, as indicated by the Spearman correlation coefficient of .48 $(\mathrm{p}<.001)$.
} 
"startup" costs (e.g., no need to move or establish new networks of contacts), the feeling that the kibbutz is home, and the desire to live close to family members. ${ }^{19}$

A second, complementary explanation for this finding follows from the insight that new members may feel the need to prove themselves as loyal and worthy members. In this aim, new kibbutz members may display in abundance the most desirable group characteristics, not the least of which is cooperative behavior toward other members. Along similar lines, social psychologists have noted that in-group favoritism shown by new group members tends to wane over time as favorable stereotypes about in-group members are replaced with more realistic perceptions (see for example, Ryan and Bogart, 1997, and references therein).

\section{Discussion}

Experimental research in economics is overwhelmingly conducted on university students. While student subjects offer numerous advantages, ${ }^{20}$ there are many research questions that are better addressed with non-students. In this paper, we design an incentivized field experiment to test the in-group-out-group bias in cooperative behavior. The population we chose, Israeli kibbutz members, depends on mutual cooperation to survive as a group. The experiment we designed resembles the environment in which kibbutz members regularly cooperate with one another.

Several reasons led us to believe that kibbutz members would be equally cooperative toward outsiders. Plausible reasons notwithstanding, our results show that even in a community where in-born members are raised to sacrifice for the good of society and later-joining members are highly idealistic, individuals demonstrate a strong in-group favoritism in cooperation.

\footnotetext{
${ }^{19}$ Indeed, regarding this last reason, in the post-experiment questionnaire, we asked kibbutz members for the number of other households on the kibbutz in which they or their spouse have family members. Those born on the kibbutz report on average 3.7 (median=3.0) other households with family members compared to only 2.1 (median=2.0) households for those not born on the kibbutz, $\mathrm{t}$-stat $=3.22, \mathrm{p}=.002, \mathrm{df}=40$.

${ }^{20}$ For example, students are on the whole intelligent, fast learners, computer literate (useful in the case of computerized experiments) and very accessible. Their accessibility to university researchers permits ease of
} 
Perhaps even more surprising, kibbutz members are no more cooperative than city residents when the two are paired with one another.

There is room to interpret kibbutz members' selective cooperation in a more favorable light. Carpenter (2000) develops a model that emphasizes the value of an in-group-out-group bias in dealing with collective-action problems. Reciprocity, trust and the expectation that others will cooperate allow group members to select institutional rules to overcome social dilemmas. That kibbutz members display a greater willingness to cooperate with one another than with outsiders may account, in part, for the longevity of the kibbutz and its apparent success at managing common-pool resources. Broadly stated, kibbutz members appear able to tailor their cooperative behavior to the situation: when paired with those who share a common fate - a fate highly dependent on cooperation - levels of cooperation are higher than when paired with outsiders. Moreover, that kibbutz members are no more cooperative than city residents implies that kibbutz members are not blindly cooperative or "suckers", but rather are able to adjust their cooperativeness to match that of those with whom they interact.

There are at least three possible sources for the selective cooperation displayed by kibbutz members in our game. First, in the kibbutz-kibbutz treatment, subjects know their fellow kibbutz members, even though they don't know with whom among them they are paired. Thus, it may be that kibbutz members have learned from experience that cooperation tends to be reciprocated. The finding that the predict variable is lowest in the kibbutz-kibbutz treatment supports this explanation. By contrast, in the kibbutz-city treatment, a kibbutz member knows nothing about his paired city resident. Worse yet, most kibbutz members likely believe that outsiders are less cooperative than their fellow kibbutz members. In fact, the very decision to

replication by other researchers. They also constitute a diversified subject pool by some measures and earn relatively low outside wages making them affordable subjects. 
join the kibbutz may reflect a distrust or disillusionment with the surrounding Israeli capitalist culture.

Second, the changes that the Israeli kibbutz underwent following the economic crisis of the mid-1980s damaged the universally cooperative and self-sacrificing fabric of even the most cooperative kibbutzim. Indeed, the kibbutz no longer plays the dominant role it once did in social causes and involvement in Israeli society. Although many kibbutzim emerged seemingly unscathed from the crisis (including the four kibbutzim chosen for our sample), their interaction with other kibbutzim and with an increasingly competitive and individualistic Israeli society appears to have left its mark.

Third, in the kibbutz-kibbutz treatment, members may be behaving as if they are playing a supergame. In other words, kibbutz members may be concerned about the impact of their decisions on future interactions with their fellow kibbutz members. A kibbutz member may choose to remove a relatively modest amount so as not to pollute (further) the existing cooperative environment on the kibbutz. This concern does not exist when a kibbutz member is paired with a city resident.

\section{Conclusions}

Unlike individuals living in capitalist economies who rely on property rights, contracts and an advanced legal system to achieve economic efficiency, members of collective societies depend on mutual cooperation to achieve their economic goals. We have selected one of the most cooperative and enduring collective societies in existence, the Israeli kibbutz, to examine the cooperative behavior of its members. Kibbutz members have intentionally opted out of mainstream society to pursue an ideology of cooperation. Moreover, the history of the kibbutz may be viewed as one of sacrifice for the overall benefit of Israeli society. Historically, kibbutz 
members played a central role in the establishment and defense of the State of Israel and they continue to be disproportionately involved in social and national causes.

Despite the promise of a universally cooperative group, kibbutz members cooperate more with members of their own kibbutz than with city residents. What is more, when paired with one another, kibbutz members and city residents exhibit identical levels of cooperation. In this sense, kibbutz members may be said to be conditionally cooperative individuals. Our findings attest to the strength of the psychological foundations of in-group-out-group biases, in spite of a society's efforts to train its members otherwise. Even members of this once idyllic, voluntary, cooperative community do not treat all individuals alike. Instead, they appear to form expectations concerning others' degree of cooperation and reciprocate in kind.

\section{References}

Becker, G. (1957) The Economics of Discrimination. University of Chicago Press, Chicago.

Ben-Rafael, E. (1997) Crisis and Transformation: the Kibbutz at Century’s End. State University of New York Press, Albany, NY.

Brewer, M. and D. Campbell (1976) Ethnocentrism and intergroup attitudes: East African Evidence. Sage, Beverly Hills, CA.

Buchan, N., E. Johnson and R. Croson (forthcoming) "Let's Get Personal: An International Examination of the Influence of Communication, Culture and Social Distance on Other Regarding Preferences," Journal of Economic Behavior and Organization.

Carpenter, J. (2000) "Negotiation in the Commons: Incorporating Field and Experimental Evidence into a Theory of Local Collective Action," Journal of Institutional and Theoretical Economics, 156:4, 661-683.

Carpenter, J. and J. Camilo Cardenas (2004) "An Inter-Cultural Examination of Cooperation in the Commons," unpublished manuscript. 
Harrison, G. and J. List (forthcoming) "What Constitutes a Field Experiment in Economics?" in Field Experiments in Economics, (J.P. Carpenter, J.A. List and G.W. Harrison, eds.) vol. 10, JAI Press, Greenwich and London.

Hewstone, M., M. Rubin and H. Willis (2002) “Intergroup Bias,” Annual Review of Psychology, 53, 575604.

Frank, A., B. Grossman and V. Weber (1988) Who is Afraid of the Future of the Kibbutz? Kibbutz HaArtzi, Guivat Haviva [in Hebrew].

Kahane, R. (1983) "The Committed: Preliminary Reflections on the Impact of the Kibbutz Socialization Pattern on Adolescents," in The Sociology of the Kibbutz: Studies of Israeli Society. Ernest Krausz (ed.), v.2, Transaction Books, New Brunswick, NJ.

Mann, L., M. Radford and C. Kanagawa (1985) "Cross-Cultural Differences in Children's Use of Decision Rules: A Comparison Between Japan and Australia," Journal of Personality and Social Psychology, 49:6, 1557-1564.

Nash, J. (1953) “Two-Person Cooperative Games,” Econometrica, 21, 128-140.

Ostrom, E. (2000) "Collective Action and the Evolution of Social Norms," Journal of Economic Perspectives, 14:3, 137-158.

Ostrom, E., R. Gardner and J. Walker (1994) Rules, Games, and Common-Pool Resources, University of Michigan Press, Ann Arbor.

Rabbie, J. and M. Horwitz (1969) "The arousal of ingroup-outgroup bias by a chance win or loss," Journal of Personality and Social Psychology, 13:3, 269-277.

Rabin, M. (1993) "Incorporating Fairness into Game Theory and Economics," American Economic Review, 83:5, 1281-1302.

Ryan, C. and L. Bogart (1997) "Development of New Group Members' In-Group and Out-Group Stereotypes: Changes in the Perceived Group Variability and Ethnocentrism," Journal of Personality and Social Psychology, 73:4, 719-732. 
Schram, A. (2000) "Sorting out the Seeking: The Economics of Individual Motivations," Public Choice, $103,231-258$.

Tajfel, H., M. Billig, R. Bundy and C. Flament (1971) "Social Categorization and intergroup behavior," European Journal of Social Psychology, 1:2, 149-178.

\section{Appendix A - Presentation of Results}

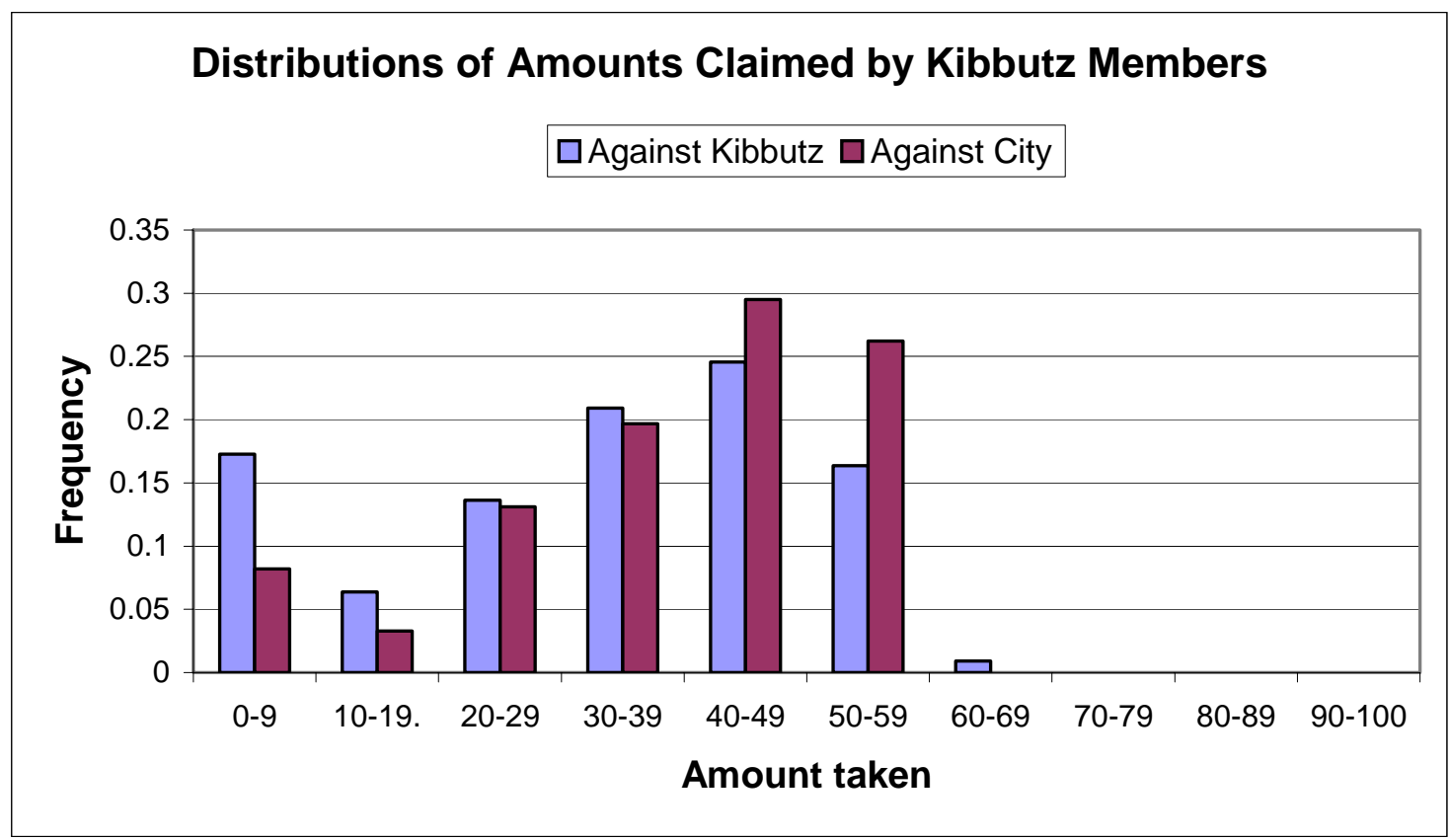

Figure 1: Histograms displaying the distributions of the amounts taken by kibbutz members when they are paired against other kibbutz members $(n=110)$ and against city residents $(n=61)$. 


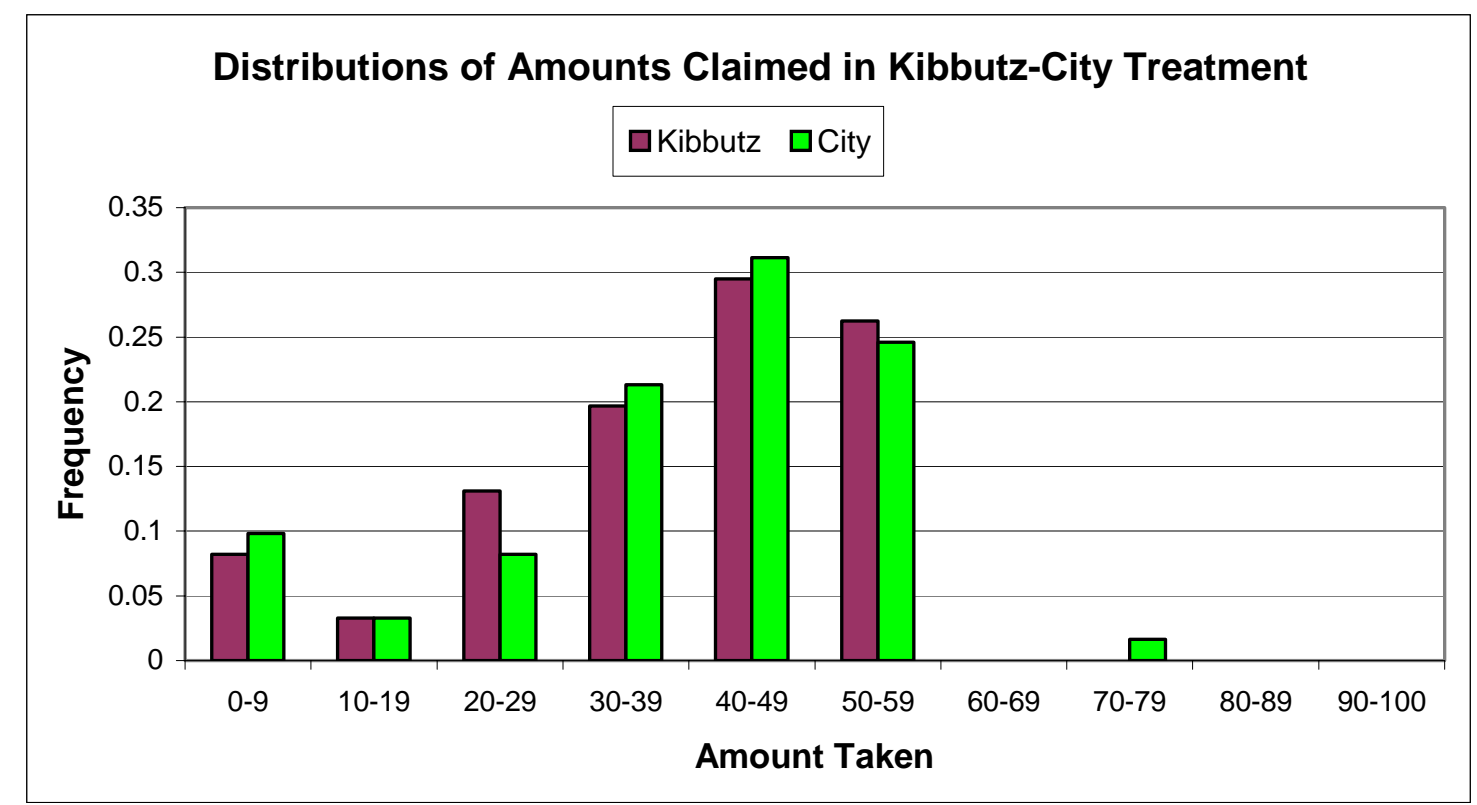

Figure 2: Histograms displaying the distributions of the amounts taken by kibbutz members when paired against city residents $(n=61)$ and by city residents when paired against kibbutz members $(n=61)$.

\begin{tabular}{|l|l|l|l|l|l|l|l|l|}
\hline population & $\begin{array}{l}\text { amount } \\
\text { taken }\end{array}$ & predict & male & age & education & $\begin{array}{l}\text { born on a } \\
\text { kibbutz }\end{array}$ & $\begin{array}{l}\text { born in } \\
\text { Israel }\end{array}$ & $\mathrm{n}$ \\
\hline kibbutz against kibbutz & $\begin{array}{l}29.56,35 \\
(17.36)\end{array}$ & $\begin{array}{l}40.38,46.5 \\
(15.63)\end{array}$ & .51 & 49.9 & 13.8 & .30 & .53 & \\
& $(.50)$ & $(18.17)$ & $(2.8)$ & $(.46)$ & $(.50)$ & 110 \\
\hline kibbutz against city & $35.20,40$ & $41.30,50$ & .43 & 51.7 & 13.6 & .31 & .52 & 61 \\
& $(14.04)$ & $(13.10)$ & $(.50)$ & $(16.39)$ & $(3.8)$ & $(.47)$ & $(.50)$ & \\
\hline city against kibbutz & $35.63,40$ & $43.18,50$ & .43 & 40.7 & 13.9 & .02 & .77 & 61 \\
& $(15.88)$ & $(12.58)$ & $(.50)$ & $(13.7)$ & $(2.8)$ & $(.13)$ & $(.42)$ & \\
\hline
\end{tabular}

Table 1: Descriptive statistics. Means (medians, and standard deviation in parentheses, where indicated) for amounts taken from the envelope (in shekels), amounts the subject believes his opponent will take ("predict") (in shekels), fractions of males, age, years of education and fractions of subjects born on a kibbutz and born in Israel for the three different groups in the experiments. 


\begin{tabular}{|c|c|c|c|c|}
\hline sample population & $\begin{array}{c}\text { all } \\
\text { subjects }\end{array}$ & $\begin{array}{c}\text { all } \\
\text { subjects }\end{array}$ & $\begin{array}{c}\text { kibbutz } \\
\text { members }\end{array}$ & $\begin{array}{l}\text { kibbutz } \\
\text { members }\end{array}$ \\
\hline variablelequation & (1) & $(2)$ & (3) & $(4)$ \\
\hline constant & $\begin{array}{l}35.20 \\
(1.79)\end{array}$ & $\begin{array}{l}10.57 \\
(2.87)\end{array}$ & $\begin{array}{l}13.66 \\
(6.61)\end{array}$ & $\begin{array}{c}0.20 \\
(3.08)\end{array}$ \\
\hline kibbutz ingroup & $\begin{array}{l}-5.63^{\star *} \\
(2.44)\end{array}$ & $\begin{array}{l}-5.01^{\star *} \\
(2.11)\end{array}$ & $\begin{array}{l}-9.03^{\star} \\
(5.47)\end{array}$ & --- \\
\hline city resident & $\begin{array}{c}0.43 \\
(2.71)\end{array}$ & $\begin{array}{l}-0.60 \\
(2.35)\end{array}$ & --- & --- \\
\hline 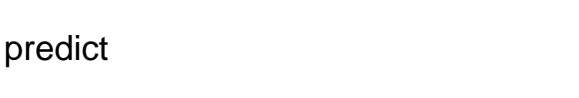 & --- & $\begin{array}{l}0.59^{* \star *} \\
(0.06)\end{array}$ & $\begin{array}{l}0.56^{\star \star *} \\
(0.08)\end{array}$ & $\begin{array}{l}0.61^{\star * *} \\
(0.07)\end{array}$ \\
\hline frackib*kibbutz ingroup & --- & --- & $\begin{array}{c}10.21^{* *} \\
(4.95)\end{array}$ & --- \\
\hline frackib*kibbutz outgroup & --- & --- & $\begin{array}{c}2.81 \\
(5.51)\end{array}$ & --- \\
\hline age & --- & --- & $\begin{array}{l}-0.07 \\
(0.07)\end{array}$ & --- \\
\hline born on kibbutz*kibbutz ingroup & --- & --- & --- & $\begin{array}{l}6.05^{\star} \\
(3.15)\end{array}$ \\
\hline born on kibbutz*kibbutz outgroup & --- & --- & --- & $\begin{array}{l}8.37^{\star \star \star} \\
(2.77)\end{array}$ \\
\hline (1-born on kibbutz)^kibbutz outgroup & --- & --- & --- & $\begin{array}{l}5.86^{\star \star} \\
(2.44)\end{array}$ \\
\hline years on kibbutz & --- & --- & --- & $\begin{array}{l}0.10^{*} \\
(0.06)\end{array}$ \\
\hline adjusted $R^{2}$ & .024 & .287 & .305 & .307 \\
\hline $\mathrm{n}$ & 231 & 231 & 170 & 170 \\
\hline
\end{tabular}

The dependent variable is the amount removed from the envelope by the subject.

$* * *$ The coefficient is significant at the $1 \%$ level.

** The coefficient is significant at the 5\% level.

* The coefficient is significant at the $10 \%$ level.

Table 2: OLS regression coefficients (heteroskedasticity-robust standard errors in parentheses) for all subjects' pooled decisions (regressions (1) and (2)) and for kibbutz members only (regressions (3) and (4)). The amount a subject removed from the envelope is regressed on a dummy variable for whether the subject was a kibbutz member who played against another kibbutz member ("kibbutz ingroup") or whether the subject is city resident ("city resident"), the subject's estimate of how much his opponent will remove ("predict"), the fraction of a member's life spent on the kibbutz interacted with kibbutz members in the kibbutz-kibbutz treatment ("frackib*kibbutz ingroup") and in the kibbutz-city treatment ("frackib*kibbutz outgroup"), the member's age ("age"), dummy variables for whether the kibbutz member was born on the kibbutz ("born on kibbutz") or not ("1-born on kibbutz") interacted with kibbutz members in the two treatments, and the number of years the kibbutz member has lived on the kibbutz ("years on kibbutz"). 


\section{Appendix B - Subjects’ Forms (translated from Hebrew)}

Introduction (read aloud by the experimenter)

We thank you for your willingness to participate in this research conducted by Ben-Gurion University and the University of Connecticut. The exercise in which you have agreed to participate relates to decision-making and requires less than 30 minutes of your time. We assure you that during the exercise as well as after its completion and on the short questionnaire that follows the exercise, your identity will remain anonymous. The information collected by the researcher in your home will be used for research purposes only. Under no circumstance will your identity be revealed to anyone or published anywhere.

This exercise in decision-making will take place in pairs. The person with whom you are paired for the purpose of this exercise is [from another settlement in Israel /another member from your kibbutz]. Another researcher from our team is currently at the home of this person. Under no circumstance will you learn the identity of the person with whom you are paired; nor will s/he learn your identity. During the decision-making exercise, you will be asked to make a number of decisions. At the end of the exercise, the researcher will pay you an amount of money. The precise amount of money to be paid to you will be determined by the decisions you make in the exercise as well as the decisions of the anonymous person with whom you have been paired. This research is funded by a number of grants from various research foundations.

\section{Participants' Instructions}

(read first by the subject and then read aloud by the experimenter)

\section{$\underline{\text { Exercise }}$}

In this exercise, you and the [person with whom you are paired from another place in Israel / member of your kibbutz with whom you are paired] have access to the same envelope that contains 100 shekels. You must decide an amount of money you wish to remove from the envelope to keep. You may choose any amount between 0 shekels and 100 shekels, inclusive. At the same time, the [other person / member of your kibbutz] with whom you are paired for this exercise must decide an amount of money (between 0 and 100 shekels inclusive) that he or she wishes to remove from the same envelope. After you have decided how much to keep from the envelope, the researcher will convey your decision by cellular phone to the other researcher who is presently at the home of the person with whom you are paired. You and the person with whom you are paired will learn of the other's decision only after each of you has made your decision.

If the sum of the amounts you and your paired partner choose to remove from the envelope (the total amount removed) exceeds 100 shekels, then you both receive no payment and the exercise ends. If you and the person whom you are paired choose to remove from the envelope an amount that together is less than 100 shekels, then you each keep the amount you removed from the envelope; in addition, the sum of money left over increases by $50 \%$ (in other words, is multiplied by 1.5) and is divided equally between you and your paired partner.

This completes the instructions. Before you make a decision in the exercise, the researcher in front of you will read aloud the instructions an additional time and answer any questions you may have. Also, you will be shown two numerical examples in order to illustrate the exercise and to avoid any unintended loss in earnings.

Thank you - The Research Team. 